\title{
DESENVOLVIMENTO, SOCIEDADE E NATUREZA: A VIABILIDADE DE MODELOS SÓCIO-PRODUTIVOS AMAZÔNICOS
}

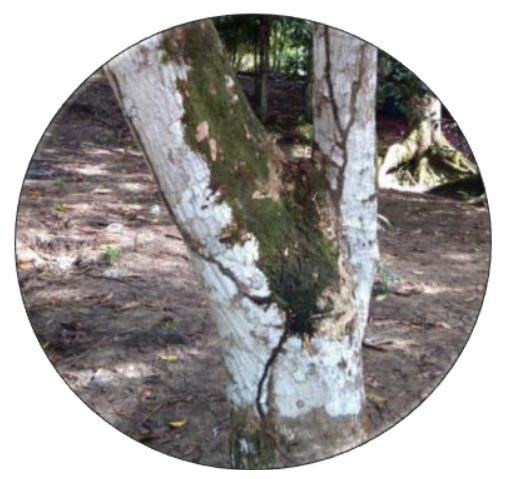

\author{
Pedro Máximo de Andrade Rodrigues ${ }^{1}$ \\ Sandra do Nascimento Noda ${ }^{2}$
}

\begin{abstract}
Resumo
O artigo visa discutir os conceitos relacionados à emergência da problemática ambiental no contexto das ciências sociais e da economia, bem como fazer uma aproximação com modelos produtivos das formações sociais amazônicas. Apresenta a análise das interações humanas e ambientais necessárias à organização de modelos sócio-produtivos indígenas na região do Alto Rio Solimões. As áreas de estudo selecionadas foram a Comunidade Indígena Novo Paraíso, de etnia ticuna, e a Aldeia Cocama Nova Aliança. A caracterização dos componentes dos respectivos modelos sócio-produtivos foi baseada, sobretudo, na percepção dos produtores agroflorestais indígenas, enquanto expressão do conhecimento vivenciado cotidianamente por eles, e na lógica e dinâmica internas que determinam as suas interações.
\end{abstract}

Palavras-chave: Etnoeconomia. Economia indígena. Economia da dádiva. Sistemas agroflorestais. Agricultura familiar. Alto Solimões.

\begin{abstract}
The paper discusses the concepts related to the emergence of environmental issues in the context of social and economic sciences, as well as making an approach to productive social formations of the Amazonian models. Presents the analysis of human and environmental interactions for the organization of indigenous socio-productive models in
\end{abstract}

1 Economista; Mestre em Ciências do Ambiente e Sustentabilidade na Amazônia; professor assistente da Universidade do Estado do Amazonas/UEA.

2 Doutora em Ecologia; Mestre em Agronomia; professora associada da Universidade Federal do Amazonas/UFAM; professora do Programa de PósGraduação em Ciências do Ambiente e Sustentabilidade na Amazônia - PPGCASA/UFAM 
the Upper Solimões River region. The areas selected for study were the Novo Paraíso Indigenous Community of ticuna ethnicity, and the Nova Aliança Village Cocama. The characterization of the components of the respective socio-productive models was based primarily on the perception of indigenous agroforestry producers as an expression of knowledge experienced daily by them, and the logic and internal dynamics that determine their interactions.

Keywords: Ethnoeconomy. Indigenous economy. Gift economy. Agroforestry systems. Family agriculture. Alto Solimões.

\section{INTRODUÇÃO}

A emergência da crise ambiental em escala global nas últimas décadas do século XX, sinalizada pelo esgotamento dos estoques de recursos naturais renováveis, alterações climáticas em escala global, desmatamentos, perda da biodiversidade e degradação dos ecossistemas planetários mais significativos, entre outros graves problemas ambientais, evidenciou o comprometimento da base biofísica de sustentação do modelo de desenvolvimento socioeconômico hegemônico nas sociedades ocidentais do planeta.

Frente a este cenário, os organismos multilaterais, governos mundiais e o movimento ambientalista referendaram o conceito de desenvolvimento sustentável como alternativa ao modelo quantitativo e monetário de crescimento econômico predominante.

O conceito de desenvolvimento sustentável e o seu derivado qualificativo, o de sustentabilidade, ainda que padecendo da falta de consenso científico e de vulnerabilidade epistêmica, pretendem articular eficiência econômica, justiça social e equilíbrio ecológico, tornando-se em ideias-força que conectam os locais e as regiões com o mundo, bem a gosto do espírito multiculturalista do processo contemporâneo de expansão capitalista conhecido como globalização.

O paradigma ambiental e os discursos globalizantes recolocaram a Amazônia no palco do mundo, reconhecida como ecossistema-símbolo, 
fonte de recursos genéticos inestimáveis a serem apropriados pelo grande capital, e nova fronteira de expansão agrícola, de espoliação mineral e madeireira no âmbito nacional.

A Amazônia, enquanto região-mundo padece da dicotomia de ser idealizada e representada como região exótica, ao mesmo tempo em que internamente sofre o descaso e a incapacidade históricas do Estado Nacional em propor-lhe um amplo projeto de desenvolvimento de base sustentável, que leve em conta as suas características, potencialidades, especificidades e limites (SILVA, 2001).

A representação da região no imaginário popular, enquanto imensa floresta tropical úmida, permeada por rios caudalosos e "vazia de gente", não leva em conta os processos recentes de desmatamento intensivo, a surpreendente "seca" verificada no ano de 2005, a presença milenar dos povos indígenas na região, e dos seus legítimos herdeiros, as populações caboclas ribeirinhas, em sua maior parte estabelecidas no ecossistema de Várzeas, ambiente cuja fertilidade dos solos depende dos ciclos anuais de cheia e vazante dos rios da Bacia Amazônica.

A identificação e o reconhecimento dos níveis de interação adaptativa existente entre os processos sócio-produtivos das populações indígenas, caboclas, ribeirinhas e a dinâmica, o ritmo e os processos ecológicos nos Ecossistema de Várzea e Terra Firme, podem fornecer os parâmetros necessários à valorização de estratégias próprias de organização econômica e reprodução social, do conhecimento presente nas tecnologias e técnicas de manejo dos recursos naturais por elas desenvolvidas, e da relevância da sua intervenção na formação, organização e preservação das paisagens amazônicas. Esta proposição apresenta-se como uma alternativa real e historicamente vivida pelas populações amazônicas, que prestam serviços ambientais de preservação e conservação dos estoques de capital natural da região (FEARNSIDE; POSEY, 1997). 


\section{Meio ambiente e crise ambiental}

O termo meio ambiente foi cunhado a partir da sintomatologia crescente de problemas ecológicos locais ou de natureza sistêmica, revelados à percepção humana geral e em seguida transformados em objeto do conhecimento científico, particularmente a partir da década de 60 do século XX. Para esse processo de reconhecimento do ambiente e do surgimento da Revolução Ambiental, algumas obras literárias exerceram papel fundamental, tais como O Guia do Mochileiro das Galáxias de Douglas Adams (1979), e A Primavera Silenciosa de Rachel Carson (1962), que marcaram o início do movimento ambientalista.

Desde então, algumas reflexões têm sido feitas no sentido de se ressaltar que a racionalidade econômica firmada em escala planetária por meio dos processos contemporâneos da globalização, realiza de forma sistemática e intensiva a expropriação dos estoques de capital natural, com o fim de realizar a produção e a reprodução do capital econômico, processos fundamentais da dinâmica e lógica próprias do modo capitalista de produção.

Essa lógica econômica vem resultando em desigualdades sociais e degradação ambiental crescentes, ameaçando a sustentabilidade do sistemamundo. Dito de outra maneira, a crise ambiental evidencia a crise do processo civilizatório posto em marcha por esse modelo de desenvolvimento. Furtado (1996) já alertava para os limites do crescimento econômico indiscriminado, desarticulado do atendimento das necessidades sociais, e indiferente aos limites do meio físico natural. Para ele, a ideia do desenvolvimento econômico, principal motor ideológico do arranjo das forças produtivas em expansão, era um mito, no sentido de comportar uma falsa utopia presente nos discursos que levavam os países periféricos a realizarem enormes sacrifícios a fim de alcançar o modelo de vida das economias dos países centrais. 
Ao mesmo tempo, os questionamentos relativos aos limites da capacidade do modelo de desenvolvimento econômico em gerar bem-estar social ampliado e sustentabilidade ambiental, resultaram na elaboração do conceito de desenvolvimento social, fundamentado em critérios mais qualitativos concernentes à qualidade de vida das populações.

Numa perspectiva socioeconômica alternativa, Maurice Strong, secretário geral da $1^{\mathrm{a}}$. Conferência Mundial sobre o Homem e o Meio Ambiente, realizada em Estocolmo, em junho de 1972, lançou o termo ecodesenvolvimento. Este termo como proposto, caracterizava o desenvolvimento das populações por elas mesmas, utilizando os recursos naturais disponíveis, por meio da adaptação ao ambiente que elas transformam e se utilizam sem destruir.

Ignacy Sachs $(2004 ; 1981)$ desenvolveu e difundiu o conceito de ecodesenvolvimento, concebido como uma via intermediária entre o economicismo auto-suficiente e o ecologismo extremado, configurando um princípio orientador para a busca da justiça social em equilíbrio com a natureza e não por meio da sua depleção e contaminação. Para Sachs a busca de soluções para a problemática ambiental está na convergência das ações e na democratização das relações entre as forças do mercado, do estado e da gestão e do planejamento social dos recursos, orientados para práticas econômicas centradas no atendimento das reais necessidades das populações e na formulação de indicadores de bem-estar social e de qualidade de vida em maior equilíbrio com os processos naturais.

Dessa maneira, o ambiente emergiu do campo das externalidades para onde havia sido relegado pelo pensamento e práticas econômicas vigentes, constituindo um novo paradigma de princípios sociais e um novo potencial de desenvolvimento, baseado em novas condições culturais e tecnológicas (LEFF, 2002).

A articulação entre processos ecológicos e culturais nessa concepção de ecodesenvolvimento destaca-se como o viés inovador que 
rompe os limites paradigmáticos das ciências e promove a interdisciplinaridade na análise dos problemas e na busca de soluções para a questão ambiental, particularmente ao valorizar o papel dos processos culturais e simbólicos na construção de uma racionalidade ambiental.

O ecodesenvolvimento, a princípio, foi concebido como uma estratégia e estilo de desenvolvimento voltado à realidade dos países em desenvolvimento (a industrialização dos trópicos), para o qual deveriam ser desenvolvidas tecnologias apropriadas que possibilitassem a utilização do seu potencial econômico sem degradar ou exaurir os fluxos de recursos, baseadas na capacidade da fotossíntese das florestas tropicais em produzirem biodiversidade.

Com o desenvolvimento posterior do conceito de self-reliance (autoestima, na tradução de Fernando Henrique Cardoso), Sachs fundamenta as estratégias do ecodesenvolvimento na capacidade de autogestão das populações e das comunidades que habitam as regiões tropicais, ou seja, propõe um processo de descentralização econômica e um reordenamento do espaço produtivo. Não se trata somente de uma harmonização entre o sistema de produção e o sistema ecológico, mas, sobretudo, um empoderamento por parte das populações locais, por meio da apropriação social local dos recursos ambientais, voltada a um desenvolvimento sustentável e sustentado.

O discurso do ecodesenvolvimento foi bem acolhido na América Latina, e por aqui circulou rapidamente, alcançando acolhida junto a organismos regionais como a CEPAL, bem como em projetos de desenvolvimento de vários países.

O ecodesenvolvimento fundamenta-se no exercício de práticas democráticas e em uma racionalidade ambiental, assentadas no pluralismo cultural, na participação e autodeterminação das populações locais, na decisão sobre o manejo dos recursos naturais disponíveis em cada contexto socioambiental, propugnando estratégias socioeconômicas espaciais 
diversificadas, integrando o planejamento econômico com o espacial, defendendo dessa forma o estabelecimento de inovações institucionais no favorecimento de um sistema de planejamento estratégico descentralizado.

Desde a Conferência Mundial do Meio Ambiente em 1987, com a publicação do Relatório Nosso Futuro Comum, aprovado pela Assembleia das Nações Unidas, o termo desenvolvimento sustentável ganhou vigência política. A Rio 92 legitimou esta concepção de modelo econômico que ainda se encontra em processo de cristalização.

Afirmam Freitas e Castro Júnior (2004) que o princípio de sustentabilidade constitui-se em ideia central para a construção de uma ética moderna, voltada à preservação da espécie humana. Por outro lado, o termo não contribui para o questionamento do processo de acumulação, no qual se baseia o desenvolvimento, sustentado ou não, nem as condições do contrato social, necessárias ao seu desenvolvimento.

Em síntese, o desenvolvimento sustentável sintetiza os esforços do processo de globalização na busca de um conceito concentrador de interesses diversos, capaz de dissolver o conflito entre desenvolvimento e meio ambiente. Nessa perspectiva, o Estado agora tem a função de elemento mediador entre as empresas transnacionais e o grande capital, a sociedade civil, e as comunidades urbanas e rurais.

\section{O esverdeamento da economia: a natureza como custo}

A lógica capitalista desenvolveu tentativas teóricas a fim de internalizar os valores e potencialidades dos processos naturais à sua dinâmica, com o objetivo de gerar um processo de desenvolvimento sustentável dentro dos seus moldes. Para isso, vem se utilizando do seu referencial teórico tradicional, a economia neoclássica, agora revisitada sob a denominação de economia dos recursos naturais e economia do meio ambiente. 
A economia dos recursos naturais tem por objeto os recursos naturais renováveis ou não renováveis, enquanto a economia do meio ambiente está associada às externalidades das atividades econômicas. A economia ambiental ou dos recursos naturais estabelece a discussão com a temática ambiental, a partir do enfoque dos recursos naturais, apoiando-se em primeiro lugar no princípio da escassez.

O princípio da escassez considera como bem econômico o recurso escasso, desconsiderando o que for abundante. Disso resulta que a única forma de preservar os recursos naturais é caracterizá-los como bens econômicos ou escassos, o que significa promover a sua apropriação e capitalização.

Como os recursos naturais são bens de livre acesso, a solução proposta para a sua manutenção e preservação é a sua internalização por meio da privatização e da precificação, reduzindo-os assim à lógica de mercado. Confirmando essa premissa, Weber afirma:

Sem nos darmos conta, vivemos um movimento de fechamento, de enclosures, em escala mundial, onde o desafio estratégico se torna uma apropriação privada de tudo aquilo que existe no planeta, inclusive a atmosfera, através da tentativa de regulação pelo mercado das emissões de gases considerados indutores do "efeito estufa" (WEBER, 2002, p.117).

A outra noção importante enfocada pela economia do meio ambiente é a internalização das externalidades. As externalidades representam falhas do mercado e, para sua remediação, Pigou sugeriu o estabelecimento de taxas e impostos que neutralizassem os custos externos resultantes dos danos ambientais e sociais.

A economia ecológica, por sua vez, parte de uma visão préanalítica do sistema econômico visto como subsistema aberto, em conexão com um sistema totalizante: o ecossistema global. Essa maneira de conceber os processos econômicos como fundamentados nos processos 
biofísicos é herdeira da bioeconomia, concepção formulada pelo economista romeno Nicholas Georgescu-Roegen. $\mathrm{Na}$ visão da bioeconomia, a lei da entropia representa a mais significativa restrição por impossibilitar a completa reciclagem da matéria-prima, e a não substituição entre o capital natural e o capital produtivo (STAHEL, 1995).

A abordagem convencional da teoria econômica centra-se no problema da troca de riquezas entre os agentes econômicos, enfatizando a importância da preferência dos consumidores, das tecnologias e da disponibilidade de capital para o perfeito funcionamento e equilíbrio de mercado. Ao mesmo tempo, concebe os sistemas econômicos como sistemas isolados, uma vez que os processos econômicos são descolados do contexto biofísico do qual dependem.

A economia ecológica propõe a modelagem dos elos ecológicos que determinam as interações entre os sistemas naturais e econômicos. A modelagem e caracterização dos processos sócio-produtivos podem, por exemplo, ser desenvolvidas a partir da verificação dos graus de ocorrência dos processos de entropia (degradação) ou neguentropia (regeneração) nos modelos econômicos das populações tradicionais e indígenas da Amazônia.

Considerando as estratégias de manejo e conservação dos ecossistemas, Begossi (1995; 1997) tem enfatizado a importância dos modelos produtivos praticados pelas populações tradicionais na medida da sua familiaridade com o ambiente, destacando os pontos de contato entre o campo de recursos de propriedade comum e a economia ecológica na busca de sistemas autorregulatórios.

Embora tenha integrado a ecologia na análise da sustentabilidade e da viabilidade dos sistemas e processos produtivos, a economia ecológica não considera a abordagem social dos problemas do desenvolvimento. $\mathrm{O}$ seu foco de análise é a relação do homem com a natureza. A espécie humana não é abordada pelas suas distintas classes sociais e conflitos de interesse que a conduzem a diferentes soluções para os problemas 
ambientais. Tanto na visão da economia do meio ambiente quanto na da economia ecológica, o ambiente é visto como um custo e não como potencial produtivo.

\section{Enrique Leff: ecodesenvolvimento e potencialidade produtiva do ambiente}

Para Leff (2000), tanto na visão da economia do ambiente e dos recursos naturais quanto na da economia ecológica, o ambiente aparece como limite e custo e não como potencial produtivo. Por isso, o autor propõe a construção de um novo paradigma produtivo, cujo fundamento é o ambiente. Nessa perspectiva, o ambiente constitui-se em sistema produtivo e não em uma externalidade incluída no cálculo econômico como custo do desenvolvimento ou lugar da deposição de resíduos do sistema produtivo.

Particularmente no âmbito latino-americano, a conceitualização de ambiente adquire uma concepção mais ampla de potencial produtivo e sistema de recursos sob a perspectiva de uma racionalidade ambiental e de uma produtividade ecotecnológica. Essa racionalidade está baseada na produtividade primária dos ecossistemas, na inovação de tecnologias ecologicamente sustentáveis e nos valores culturais das comunidades locais, constituindo uma visão alternativa de desenvolvimento, que articula os processos naturais, culturais e tecnológicos.

Como consequência, a questão ambiental foi deslocada do campo da planificação e das políticas públicas, para o âmbito das estratégias de poder das comunidades autogestionárias, por meio da apropriação da natureza, criando um novo campo de lutas sociais em contraposição aos interesses da empresa transnacional.

As três políticas ambientais - a do mercado, a do Estado regulador e da gestão social dos recursos - devem articular-se numa 
perspectiva transetorial na definição das formas de manejo sustentável e democrático do complexo sistema natural de recursos produtivos.

Porém, é, sobretudo no nível local da comunidade que são firmadas as bases da sustentabilidade, visto que aí concretamente são estabelecidas as condições ecológicas, políticas e culturais do desenvolvimento sustentável: "A reapropriação da Natureza traz de novo a questão da luta de classes, desta vez não sobre a apropriação dos meios industrializados, mas dos meios e condições naturais de produção.” (LEFF, 2002, p. 206; WALDMAN, 2002).

Dessa forma, as identidades étnicas das populações tradicionais e indígenas estão se restabelecendo por meio de uma racionalidade ambiental, ao mesmo tempo em que se compõem alianças contra a globalização. Caberá às agendas locais das comunidades a avaliação dos efeitos ecodestrutivos causados por diferentes agentes sociais e econômicos, bem como a avaliação sobre a forma como esses efeitos se entrelaçam com os processos de empobrecimento e marginalização da população local.

As condições de acesso, manejo e controle - ou seja, a gestão participativa - dos recursos produtivos das populações e comunidades podem se constituir em possibilidades reais de erradicação da pobreza e de melhora da qualidade de vida, constituindo uma nova forma de luta social e de exercício de uma democracia de base.

A compreensão das inter-relações entre processos históricos, econômicos, ecológicos e culturais constitui a base fundamental do planejamento de políticas ambientais para um desenvolvimento sustentável baseado no manejo integrado de recursos naturais, tecnológicos e culturais da sociedade, seja ela entendida na escala de um país, região ou cidade, assim como também de uma comunidade ribeirinha das várzeas amazônicas.

Existem relações de interdependência e circularidade construtiva (MORIN, 2001) entre processos sociais e ecológicos que condicionam o 
potencial produtivo dos recursos de uma formação social, seus níveis de produtividade e as condições de preservação e regeneração dos recursos naturais.

De acordo com Vieira e Weber (2002), os sistemas socioambientais são permeados pela complexidade definidora do ambiente, e necessitam ser reorganizados e informados por meio do trabalho científico mediante o registro da diversidade de conhecimentos ecológicotradicionais, e pelo exercício da mediação de conflitos em torno das diferentes concepções e respostas dadas à questão da crise ambiental.

\section{Etnoeconomia: o pensamento econômico como suporte aos sistemas produtivos tradicionais}

Uma nova ferramenta disciplinar e teórica para o entendimento de como se articulam os potenciais produtivos e culturais da natureza e a sua percepção por parte de populações indígenas e tradicionais constitui a proposta da etnoeconomia na caracterização de modos alternativos de organização da vida econômica em sociedades na periferia do capitalismo. Cavalcanti (2005) nos remete às economias de dádiva, onde a troca é determinada pela existência de excedentes de alguns bens e pela necessidade de outros bens, prevalecendo a reciprocidade no comportamento social.

A partir dessa concepção, o saber ecológico tradicional realiza a função de ponte entre a economia convencional e a etnoeconomia, caracterizada particularmente por conhecimentos ligados à gestão, ao planejamento, manejo e conservação dos recursos naturais para uma produtividade sustentada de longo prazo.

Dessa forma, a etnoeconomia vem em auxílio da economia ecológica por adotar uma proposta teórica, que além de estar orientada para o desenvolvimento sustentado de longo prazo, e de considerar as limitações ecológicas em relação à noção de progresso, também considera a 
diversidade cultural e as cosmovisões das populações indígenas alicerçadas no saber ecológico tradicional.

A relevância em se caracterizar modelos econômicos não capitalistas - aos quais se costuma denominar genericamente de sociedades na periferia do capitalismo - vem atestada por Karl Polanyi, em sua obra mais significativa sobre o tema, A Grande Transformação (1944). Nessa obra, Polanyi, além, de desmistificar uma pretensa predominância do mercado na organização da vida econômica e social, destaca a pré-existência de práticas econômicas fundamentadas na reciprocidade, na permuta, na redistribuição, realizadas a partir das unidades familiares e baseadas em valores culturais, típicos dos modelos econômicos presentes nas formações sociais da Amazônia.

Nesses sistemas econômicos tradicionais, o mercado acha-se subordinado aos valores e práticas sociais e culturais, num plano totalmente inverso ao que vemos acontecer no mundo contemporâneo. Para Polanyi, até fins do século XVIII, o sistema econômico acha-se absorvido (embeddedness) pelo sistema social, naquilo que Mauss (1977) chama de fato social total.

A comunidade camponesa ou rural normalmente é dirigida por uma autoridade local (patriarca, conselho formal ou informal de anciãos ou chefes de família) que gerencia o acesso à terra e aos recursos naturais, a redistribuição ou intercâmbio de trabalho (ajuda mútua) e a solidariedade inter-familiar. Numa sociedade agrária, para dar é necessário produzir. Dessa forma, o acesso à terra e aos recursos naturais constitui também uma redistribuição dos fatores de produção.

\section{Modelos produtivos amazônicos}

A existência de uma grande desigualdade social e um acelerado processo de pauperização na região também põe problemas sobre o tipo de 
desenvolvimento mais adequado para a Amazônia, e em que modelos de produção devem estar baseados.

Salazar (2004) conceitua modelos de produção como sendo estruturas econômicas setorizadas nas quais se acham inseridos os meios de produção (instrumentos de trabalho, tecnologia, terra, recursos naturais e formas de organização do trabalho produtivo), constituindo formas particulares de realização da atividade econômica e de organização dos fatores produtivos, que por sua vez acham-se inseridos em um determinado modo de produção.

Em relação à organização do sistema produtivo e as formas de circulação dos bens necessários à reprodução das formações sociais encontradas na Amazônia, estas apresentam características muito semelhantes entre si, sendo fundamentalmente baseadas na quantidade da força de trabalho familiar.

As atividades produtivas acham-se organizadas em ambientes pouco modificados, sendo os sistemas de produção característicos do tipo sistemas agroflorestais (SAFs) (SANTOS, 2004).

As atividades de produção são organizadas em unidades produtivas ou componentes. Conforme descrição de Rodrigues (2009) e Noda (2000) estes são os componentes que constituem esses sistemas produtivos: i. roça ou roçado: local onde são cultivadas as espécies anuais durante algum período e, depois disso, o solo é deixado em descanso, para a recuperação da fertilidade e a eliminação de plantas invasoras; ii. sítio, terreiro ou quintal: onde são cultivadas as espécies frutíferas, hortaliças, espécies medicinais e, eventualmente, essências florestais; iii. caça; iv. pescaextrativismo animal (caça e pesca); iv. extrativismo vegetal; v. criação de animais; vi. artesanato.

Em diversos sistemas produtivos, o cultivo de algumas culturas agrícolas, tais como a mandioca e a banana destacam-se como mais 
importantes nas unidades de produção, seja pelo valor cultural de uso, seja pela produção de excedentes para venda nos mercados circundantes.

No componente sítio ou terreiro estão envolvidos o manejo de árvores, arbustos e ervas de usos múltiplos, intimamente associados a cultivos agrícolas anuais e perenes e, a criação de animais doméstico de pequeno porte. Esse manejo se deve à mão de obra familiar, com especial destaque ao papel das mulheres e crianças.

A carne de caça é o alimento mais importante no fornecimento de proteína, depois do peixe. A caça, basicamente, destina-se ao atendimento das necessidades alimentares das famílias e, eventualmente, à comercialização. O peixe é o principal alimento protéico dos ribeirinhos amazônicos e a atividade de pesca é a que consome maior tempo de trabalho do produtor, depois da agricultura. O extrativismo vegetal é realizado na floresta e constitui um elemento permanente da paisagem. Os produtos extraídos são: alimentos, condimentos, remédios, aromáticos, madeiras e fibras. Os produtos são extraídos, principalmente, para consumo próprio das populações.

Nas comunidades há uma pequena criação de animais, destacando-se a de aves (galinhas e patos), os suínos e os ovinos (carneiros). Esses animais são criados soltos nas comunidades, alimentando-se em sistema de pastejo direto e, complementarmente, de restos de comida.

Em razão de uma vivência muito próxima e extremamente dependente dos recursos genéticos que a Floresta Amazônica oferece, esses grupos humanos desenvolveram um conhecimento apurado sobre esses recursos, desenvolvendo alimentos, pesticidas, remédios, artesanato, a partir de uma união entre recurso genético e conhecimento (NODA, 2000; WITKOWSKI, 2007).

Constata-se que o conhecimento (saber tradicional), de uma maneira geral, ainda é passado de geração em geração por meio de 
transmissão oral, não havendo registros escritos, o que leva a uma maior valorização das pessoas idosas da comunidade, mesmo que muitos deles já tenham sido escolarizados na atualidade. Porém, não possuem o costume da escrita como acontece com as sociedades ocidentais.

De um modo geral, ressalta-se o interesse dessas comunidades em transmitir seus conhecimentos para as gerações futuras, bem como obter cada vez mais conhecimentos, preservando-os e obtendo proveito econômico.

\section{Considerações Finais}

As populações amazônicas tradicionais indígenas e não indígenas têm demonstrado uma grande capacidade de interagir com o ambiente da floresta pluvial e dela extrair os recursos necessários à sua manutenção e reprodução física e cultural, encontrando estratégias próprias de organização social, cultural e econômica face à indiferença histórica do governo e da sociedade nacional em promover a sua inserção nos processos de desenvolvimento.

A emergência do critério de sustentabilidade ambiental veio conferir valor e reconhecimento social às economias alternativas de planejamento local e descentralizado, baseadas na potencialidade produtiva dos recursos ambientais.

Tomando como parâmetro os modelos econômicos das formações sociais de populações indígenas de Nova Aliança (kokama) e de Novo Paraíso (ticuna), na região do Alto Solimões, Noda (2000), Torre (2001) e Rodrigues (2008) constataram que a vida nessas comunidades, no que se refere às redes parentais e econômicas, acha-se baseada na forte concepção de coletividade e senso comum, que facilita o compartilhamento de conhecimentos e os obriga a ter um raciocínio integrado pela qual se 
torna possível a gestão coletiva dos recursos naturais disponíveis nos territórios que habitam.

Portanto, não podemos aplicar instrumentos frutos de uma situação social e econômica tipicamente capitalista para grupos humanos que possuem outro estilo de vida.

Visto que a lógica que rege as relações econômicas é preponderantemente a da dádiva e da reciprocidade, a possibilidade de se participar plenamente dos processos econômicos é dada pela possibilidade de produzir. Dessa maneira, o acesso assegurado ao ambiente e aos recursos naturais também é uma forma de se realizar a distribuição desses dons concedidos pela natureza.

Verifica-se também que as práticas produtivas e as relações econômicas estão contidas no interior da ordem social, mesmo quando a produção está orientada ou é estimulada pelo sistema de mercado. Os objetivos que as orientam estão voltados à reprodução do grupo social nas expressões do seu modo de vida e da sua cultura.

A continuidade dos modelos econômicos amazônicos enquanto forma da concretização de modelos alternativos etnoecodesenvolvimentistas dependerá da validação e inserção dos seus princípios nas políticas públicas locais, regionais e nacionais, e do respeito à autonomia dessas populações em realizarem a autogestão do seu modo de vida e dos recursos disponíveis.

\section{Referências}

ADAMS, Douglas. O Guia do Mochileiro das Galáxias. Sextante, 2009.

BEGOSSI, Alpina. Escalas, Economia Ecológica e a Conservação da Biodiversidade. In: CAVALCANTI, Clóvis (org.). Meio Ambiente, Desenvolvimento Sustentável e Políticas Públicas. São Paulo: Cortez Editora, 1997. 
CAVALCANTI, Clóvis. Pensamento Econômico, Saber Ecológico Tradicional e Etnoeconomia: uma Proposta Introdutória de Nova Perspectiva Disciplinar.Disponível em: <http://www.fundaj.govr.br/tpd/110.html > . Acesso em: 17 outubro 2005.

FEARNSIDE, Philip M. et al. Serviços Ambientais como Estratégia para o Desenvolvimento Sustentável na Amazônia Rural. In: CAVALCANTI, Clóvis (org.). Meio Ambiente, Desenvolvimento Sustentável e Políticas Públicas. São Paulo: Cortez Editora, 1997.

FREITAS, Marcílio de; CASTRO JÚNIOR, Walter Esteves. Amazônia e Desenvolvimento Sustentável: um diálogo que todos brasileiros deveriam conhecer. Petrópolis: Vozes, 2004.

FURTADO, Celso. O Mito do Desenvolvimento Intocado. $3^{\mathrm{a}}$ ed. Rio de Janeiro: Paz e Terra, 1996.

LEFF, Enrique. Epistemologia Ambiental. 2a ed.. São Paulo: Cortez, 2002.

LEFF, Enrique. Saber Ambiental: Sustentabilidade, Racionalidade, Complexidade, Poder. $3^{\mathrm{a}}$ ed. Petrópolis: Editora Vozes, 2001.

LEFF, Enrique. Ecologia, Capital e Cultura - Racionalidade Ambiental, Democracia Participativa e Desenvolvimento Sustentável. Blumenau. FURB, 2000.

MAUSS, Marcel. Ensaio sobre a Dádiva: Forma e Razão da Troca nas Sociedades Arcaicas. In: Mauss, Marcel. Sociologia e Antropologia. São Paulo: Cosac \& Naify, 2003.

MORIN, Edgar. Ciência com Consciência. $5^{\mathrm{a}}$ ed. Rio de Janeiro: Bertrand Brasil, 2001.

NODA, Sandra do Nascimento. Na Terra como na Água: Organização e Conservação de Recursos Naturais Terrestres e Aquáticos em Uma Comunidade da Amazônia Brasileira. 2000. 182f. Tese (Doutorado em Ecologia) - Instituto de Biociências, Universidade Federal de Mato Grosso, Cuiabá.

POLANYI, Karl. A Grande Transformação: as origens da nossa época. 9a . edição. Rio: Editora Campus, 2000.

POSEY, Darrel A. Exploração da Biodiversidade e do Conhecimento Indígena na América Latina: Desafios à Soberania e à Velha Ordem. In: 
CAVALCANTI, Clóvis (org.). Meio Ambiente, Desenvolvimento Sustentável e Políticas Públicas. São Paulo: Cortez Editora, 1997.

RODRIGUES, Pedro Máximo de Andrade. Homens e mulheres nas beiras: etnoeconomia e sustentabilidade no alto rio Solimões. 2009. 145 f. Dissertação (Mestrado em Ciências do Ambiente e Sustentabilidade na Amazônia) Centro de CiGencias do Ambiente, Universidade Federal do Amazonas, Manaus.

SACHS, Ignacy. Do Crescimento Econômico ao Ecodesenvolvimento. Disponível em: < http://www.cfh.ufsc.br/ $\sim$ nmddo crescimento economico ao ecod. htm>. Acesso em: 26 outubro 2004.

SACHS, Ignacy. Ecodesenvolvimento: crescer sem destruir. Trad. de E. Araujo. São Paulo: Vértice, 1981.

SALAZAR, Admilton Pinheiro. Amazônia: Globalização e Sustentabilidade. Manaus: Editora Valer, 2004.

SANTOS, Mário Jorge Campos dos. Viabilidade Econômica em Sistemas Agroflorestais nos Ecossistemas de Várzea e Terra Firme no Estado do Amazonas: um estudo de caso. Tese de Doutorado. Piracicaba: Universidade de São Paulo, 2004.

SILVA, Marilene Corrêa da. Amazônia: Região-Nação-Mundo. Manaus: EDUA, 2001.

STAHEL, Andri Werner. Capitalismo e Entropia: os Aspectos Ideológicos de uma Contradição e a Busca de Alternativas Sustentáveis. In: CAVALCANTI, Clóvis (org.). Desenvolvimento e Natureza: Estudos para uma Sociedade Sustentável. São Paulo: Cortez, 1995.

TORRE, Claudia de la. Ethno-Connaissance et Gestion des Ressources Naturelles dan une Communaute Indigene de la Municipalité de Benjamin Constant (Etat d'Amazonas, micro-région du Haut Solimões, Brésil): Ebauche d'une Strategie Integree de Conservation et Valorisation de la Diversité Fruitiere. 2001. 243 p. Dissertação (Mestrado em Agronomia) - Ecole Supépieure d'Agriculture de Purpan/ESAP, Toulouse, França.

VIEIRA, Paulo Freire; WEBER, Jacques. Introdução Geral: sociedades, naturezas e desenvolvimento viável. In: Vieira, Paulo Freire; Weber, Jacques 
(orgs.). Gestão de Recursos Naturais Renováveis; novos desafios para pesquisa ambiental. São Paulo: Cortez, 2002.

WALDMAN, MAURÍCIO. Ecologia e Lutas Sociais no Brasil. São Paulo: Contexto, 2002.

WEBER, Jacques. Gestão de Recursos Renováveis: Fundamentos Teóricos de um Programa de Pesquisas. In: Vieira, Paulo Freire; Weber, Jacques (orgs.). Gestão de Recursos Naturais Renováveis; novos desafios para pesquisa ambiental. São Paulo: Cortez, 2002.

WITKOVSKI, Antonio Carlos. Florestas de Trabalho: os Camponeses Amazônicos de Várzéa e as Formas de Uso de seus Recursos Naturais. Disponível em:<http://www.anppas.org.br/encontro_anual/encontro2/GT/GT08/a ntonio_witkowski.pdf $>$. Acesso em: 23 nov. 2007. 